\title{
BCG OVERDOSAGE TREATED WITH ISONIAZID
}

\author{
A. H. GRIffith, M.B., B.S., D.P.H. \\ Senior Medical Officer, Cardiff City Council
}

IsONIAZID is used for the treatment or prevention of tuberculosis under three different conditions, namely, when clinical manifestations of active disease are present, when infected individuals are considered to have active but not radiographically demonstrable lesions and when uninfected persons are likely to be exposed to virulent infection. The efficacy of isoniazid treatment of disease has already been well established, but there is no general agreement on its role as a prophylactic agent. The main objection to its use in the prevention of clinical disease is that the vast majority of those treated with the drug over the necessary period of several months would not have developed the disease anyway. There can hardly be any doubt, however, that under certain conditions isoniazid therapy prevents the development of progressive disease.

Isoniazid therapy has been shown to be effective in preventing progressive disease in laboratory animals if treatment is started before or immediately after infection with virulent organisms has occurred (Rich, 1950; Barnett, Bushby and Mitchison, I953; Pasquier and Mauro, 1960; Tai, Jen, Chu and Han, I96r). Animals infected with virulent organisms and treated with isoniazid resisted re-infection well, even when no longer under drug treatment (Ferebee and Palmer, I 956; Tai and others, 196r), but it is uncertain how long this state of immunity persists after the administration of the isoniazid has been discontinued.

The efficiency of isoniazid prevention depends, however, on the size of the infecting dose. It is less effective against large-dose infections than against small doses (Peizer, Chaves and Widelock, 1957). Infection with very low doses of virulent tubercle bacilli, which would otherwise produce immunity in animals, has no immunizing effect if they are treated with isoniazid (Dubos and Schaefer, 1956). Thus, isoniazid will completely suppress an infection with a small number of tubercle bacilli, so that the animal remains as if it had not been infected. Larger infections with virulent organisms are controlled by the drug and a state of immunity comparable to that found क्ष the BCG-vaccinated is produced. When the infecting dose is increased further, the efficiency of isoniazid in preventing progressive disease deteri\&rates correspondingly. It may be, however, thot the efficiency of isoniazid in suppressing or cointrolling tuberculous infection is more closely related to the number of isoniazid-resistant organisms in the infection rather than to the total number of organisms.

The development of immunity following va cination with attenuated organisms was, at firs, considered to be adversely affected by isoniazid treatment (Dubos, Pierce and Schaefer, I $\$$ but evidence to the contrary was presented tater (Bloch and Segal, 1955). Indeed, BCG-vaccinted animals treated with isoniazid were found fo possess a greater degree of immunity to virule at infection than vaccinated but untreated animas (Mauro and Pasquier, 1961). When only sm\$1 doses of BCG were used for vaccinating animas, treatment with isoniazid prevented the development of post-vaccination immunity (Dubos apd Pierce, 1956). It appears, therefore, that isoniazis therapy has a similar effect on all tubercle bacidi infections, whether they are BCG or virule $\overrightarrow{\text { int }}$ organisms, suppressing completely small dose irsfections and controlling larger dose infections without preventing the development of immunito. The effect on an infection with either BCG of virulent organisms is as if all or a large proportion of the infecting isoniazid-sensitive bacilli ape destroyed immediately, thus reducing correspondingly the effective size of the infection. N

It is not surprising, therefore, that the degree of post-vaccinal tuberculin sensitivity found in BCW vaccinated guinea pigs, which had been treated with isoniazid immediately after vaccination, ws less than in vaccinated animals which had not been treated (Jankov, I959). In guinea pigs which had been infected with virulent organisms and treated with isoniazid, $14 \%$ were tuberculin negative 36 weeks later (Peizer, Chaves and Middlebrook, 1957). Isoniazid therapy increase 
TABLE I

Diameters of Vaccination Scars and Mantoux Reactions in Ten Children Given High Doses of BCG and Treated With Isoniazid

\begin{tabular}{|c|c|c|c|c|c|c|c|c|}
\hline \multirow{3}{*}{$\begin{array}{l}\text { Age of } \\
\text { Child }\end{array}$} & \multirow{3}{*}{$\begin{array}{l}\text { Prescribed daily } \\
\text { dose isoniazid } \\
\text { (mg.) }\end{array}$} & \multirow{3}{*}{$\begin{array}{l}\% \text { Prescribed } \\
\text { tablets recovered } \\
\text { later unconsumed }\end{array}$} & \multicolumn{6}{|c|}{ Diameter (mm.) of } \\
\hline & & & \multicolumn{4}{|c|}{$\begin{array}{l}\text { ant. and post. BCG } \\
\text { scars after }\end{array}$} & \multicolumn{2}{|c|}{$\begin{array}{c}\text { Mantoux reactions } \\
\text { after }\end{array}$} \\
\hline & & & & weeks & 36 & weeks & 9 weeks & 36 weeks \\
\hline 3 & 100 & 37 & 5 & -5 & 7 & -7 & 5 & 10 \\
\hline 8 & 200 & Nil & 0 & -0 & 0 & -0 & 6 & 3 \\
\hline 13 & 300 & 48 & 12 & -6 & 10 & -5 & 12 & I I \\
\hline 13 & 300 & 43 & 5 & -4 & 4 & -3 & & 6 \\
\hline 13 & 300 & 14 & 7 & - 0 & 7 & - 0 & 3 & I I \\
\hline 13 & 300 & I I & 5 & -5 & 6 & -6 & 2 & 5 \\
\hline 13 & 300 & IO & 10 & -7 & 10 & -5 & 10 & I I \\
\hline 13 & 300 & Nil & 7 & -6 & 9 & -9 & & I I \\
\hline 13 & 300 & Nil & 5 & -6 & 7 & -7 & 0 & I I \\
\hline 13 & 300 & Nil & 2 & -0 & 2 & -0 & 0 & 2 \\
\hline
\end{tabular}

the tuberculin reversion rate also in tuberculinpositive infants (Robinson, Meyer and Middlebrook, 1955) and children (Dahlstrom, Wilson and Sedlacek, I960). Even in patients suffering from active tuberculosis there was a reduction in tuberculin allergy following antibiotic treatment (Collas, Appeau, Dhenin, Gelain and Pelletier, 1960). In the United States Public Health Service study, however, only small decreases occurred in the tuberculin sensitivity of children with primary tuberculosis treated with isoniazid (Ferebee, Mount and Anastasiades, 1957).

The conclusions drawn from these studies indicate that the efficacy of isoniazid treatment against simultaneous infection with isoniazidsensitive organisms in man could be assessed by starting isoniazid treatment immediately after BCG vaccination and determining its effect on the development of post-vaccinal tuberculin sensitivity.

An accident necessitating this treatment occurred at a BCG clinic in Cardiff during 1962, when ten children were vaccinated with a BCG suspension which had a viability count of 93 million $/ \mathrm{ml}$. instead of the usual count of between 5 and 9 million $/ \mathrm{ml}$. (Griffith, 1963). Eight of the ten children were 13-year-old girls and the other two were boys, a diabetic aged ro and a 3-year-old. Each child received two inoculations of $0.05 \mathrm{ml}$. each of this concentrated suspension, into the skin over the anterior and posterior border of the insertion of the left deltoid. They thus received a total of 9.3 million viable units of BCG instead of the usual dose of between 0.5 and 0.9 million viable units, that is, between ten and 20 times the normal dose.

Three days after vaccination the children were given exactly 30 days' supply of isoniazid; the 13-year-old girls were to receive $300 \mathrm{mg}$. daily, the ro-year-old boy $200 \mathrm{mg}$. and the 3-year-old
$100 \mathrm{mg}$. After 28 days they were given another 30 days' supply. On the 63 rd day an attempt was made to recover all unconsumed isoniazid tablets, but it is suspected that some parents claimed that all had been consumed when, in fact, this was not the case. A Mantoux test, 5 T.U. O.T., was also carried out on the 63 rd day on nine of the children and the diameter of the BCG lesions measured. The Mantoux reaction in eight of the children was read on the third day. After 36 weeks another 5 T.U. O.T. Mantoux test was carried out on the ten children and again the diameter of the BCG lesions measured (Table I).

None of the children had local abscesses or discharging sinuses when seen after vaccination, the axillary lymph glands were not palpable and the chest radiographs showed no abnormalities. The diabetic Io-year-old boy had no visible BCG lesions at any time and one girl had only one scar, with a diameter of only $2 \mathrm{~mm}$. The BCG scars measured from 0 to $12 \mathrm{~mm}$. in the other children. Four of the eight children had tuberculin reactions of less than $5 \mathrm{~mm}$. diameter after nine weeks, but only two of the ten were tuberculin negative after 36 weeks. Those with the smallest BCG scars had the least Mantoux reactions $3^{6}$ weeks after vaccination.

At the time that this accident occurred a study to compare the efficiency of intradermal and multiplepuncture BCG was in progress in Cardiff (Griffith, Kinsley and Anderson, 1963). The intradermally vaccinated participants in that study also received two inoculations of $0.05 \mathrm{ml}$. BCG suspension, each child receiving a combined total dose of 0.71 million viable units. Twelve weeks after vaccination they had BCG lesions of an average diameter of $4.9 \mathrm{~mm}$. per lesion, compared with an average diameter of $4.9 \mathrm{~mm}$. at nine weeks and $5.2 \mathrm{~mm}$. at 36 weeks in the ten isoniazid-treated children. Although the average size of the BCG 
lesions was similar in the two groups, the average Mantoux reaction in untreated children who had a normal dose of BCG was I I.I mm. after 12 weeks, compared with average diameters of $4.7 \mathrm{~mm}$. at nine weeks and $8.1 \mathrm{~mm}$. at 36 weeks in the BCGoverdosed, isoniazid-treated children. This suggests that isoniazid treatment, although not completely suppressing the initial high dose BCG infection, reduced the level of tuberculin allergy produced during the period of treatment and that, although the allergy increased after the two months' treatment was completed, it did not reach the level found at 12 weeks in children vaccinated in the normal manner. Unfortunately, however, the Mantoux reactions at nine weeks were measured by a different piactitioner from the reader at 36 weeks.

As the efficiency of isoniazid treatment i\$ animals is dependent on the size of the infecting dose, it may be presumed from this study that normal human dose of BCG or a small dose of $\vec{z}$ virulent infection could be completely suppressef

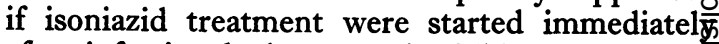
after infection had occurred. This investigatio contradicts the suggestion made (Lambert, I959 that preventive isoniazid treatment started im $^{\varphi}$ mediately after accidental laboratory inoculatio $\vec{D}$ with virulent tubercle bacilli may be ineffective and would merely prolong the incubatiofy period.

\section{REFERENCES}

Barnett, M., Bushby, S. R. M., and Mitchison, D. A. (1953): Tubercle Bacilli Resistant to Isoniazid: Virulence and Response to Treatment with Isoniazid in Guinea Pigs and Mice, Lancet, $\mathbf{i}, 314$. Bloch, H., and SEgAL, W. (I955): Viability and Multiplication of Vaccines in Immunization against Tuberculosis ${ }^{\infty}$
Amer. Rev. Tuberc., 7r, 228.

Collas, R., Appeau, A., Dhenin, J., Gelain, E., Pelletier, M. (I960): The Tuberculin Reaction under Antibiotherapy Poumon, 16, 479.

Dahlstrom, A. W. Wilson, J. L., and Sedlacek, B. (1960): The Immediate Effectiveness of Isoniazid Chemo $\mathbb{D}$ prophylaxis as Determined by the Tuberculin Test, Dis. Chest, $38,6$.

Dubos, R. J., PIERCE, C. H., and SchaEFER, W. B. (1953): Anti-tuberculosis Immunity Induced in Mice by Vaccinatio with Living Cultures of Attenuated Tubercle Bacilli, f. Exp. Med., 97, 207.

- and SchaEFER, W. B. (1956): Anti-tuberculous Immunity Induced in Mice by Virulent Primary Infectign $\overrightarrow{e 0}$ Amer. Rev. Tuberc., 74, 54r. Amer. Rev. Tuberc., 74, 541.
Rev. Tuberc., 74, 699.

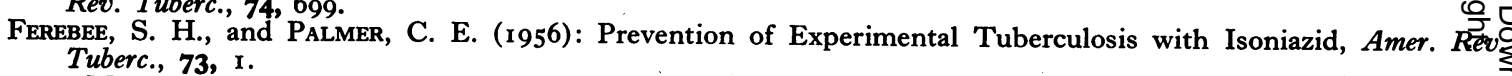

- Mount, F. W., and Anastasiades, A. N. (1957): Prophylactic Effects of Isoniazid on Primary Tuberculosio in Children, Amer. Rev. Tuberc., 76, 942.

GrIfFITH, A. H. (1963): Ten cases of BCG Overdosage Treated with Isoniazid, Tubercle, (Lond.), $44,247$. Minsley, B. J., and ANDERson, D. J. (1963): A Comparison between Multiple Puncture and Intraderma

JANkov, M. (1959): Effect of Streptomycin and Isoniazid on the Development of Allergy Induced by Various Doses of BCG Vaccine in Guinea Pigs, Tuberculoza, I1, 379.

Lambert, H. P. (1959): The Chemoprophylaxis of Tuberculosis: A Review, Amer. Rev. Resp. Dis., 80, 648.

Mauro, B., and PAsquier, J. F. (196r): Relation between Protection of BCG Vaccination and the Anti-bacterial Action of Isoniazid in Tubercular infections obtained in Mice by means of Mycobacteria labelled with C-1 $\frac{3}{3}$

Palmer, C. E., FErebee, S. H., and Hopwood, L. (1956): Studies on the Prevention of Experimental Tuberculosis with' Isoniazid, Amer. Rev. Tuberc., 74, 917.

Pasquier, J., and Mauro, B. (1960): Test for Evaluation of the Protective Power of Isoniazid Using Strain H.37 RV Tubercle Bacilli Labelled with C-14, Ann. Ist. Forlanini, 20, 105.

Peizer, L. R., Chaves, A. D., and Widelock, D. (1957): The Effects of Early Isoniazid Treatment in Experimental Guinea Pig Tuberculosis, Amer. Rev. Tuberc., 76, 732.

Robinson, A., MeYer, M., and MidDlebrook, G. (1955): Tuberculin Hypersensitivity in Tuberculous Infants treated with Isoniazid, New Engl. F. Med., 255, 983.

Rich, A. R. (1950): The Pathogenesis of Tuberculosis; Oxford: Blackwell. TAI, F. H., JEN, T. M., CHU, B. Y., and HAN, S. H. (1961): Isoniazid Prophylaxis of Tuberculous Infection in Mice ${ }_{0}$
Amer. Rev. Resp. Dis., 83, 7 I I. 